
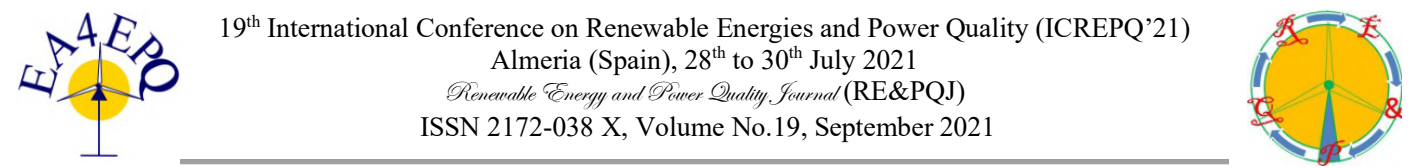

\title{
Wind Energy Education through Low-Power Wind Turbines and Advanced Software Tools
}

\author{
R. Baños ${ }^{1}$, A. Alcayde ${ }^{1}$, F.G. Montoya ${ }^{1}$, F.M. Arrabal-Campos ${ }^{1}$, A.J. Jara ${ }^{2}$ \\ ${ }^{1}$ Department of Engineering \\ E.S.I., University of Almería \\ Carretera de Sacramento s/n, La Cañada de San Urbano, 04120 Almería (Spain) \\ Phone/Fax number:+0034 950214097, e-mail: rbanos@ual.es, aalcayde@ual.es, pagilm@ual.es,fmarrabal@ual.es \\ ${ }^{2}$ HOP Ubiquitous SL \\ Luis Buñuel, 6, 30562 Ceutí, Murcia (Spain) \\ Phone/Fax number:+0034 627228126, e-mail: jara@hopu.org
}

\begin{abstract}
Wind energy has become a major source of power generation in recent years. This fact, along with the growing expectations for future decades, makes the study of renewable generation systems based on wind energy a subject of great importance for engineers from different disciplines. Although there are numerous research articles that deal with the technoeconomic aspects of this type of system, there are few works focused on the development of new didactic strategies to improve the academic excellence of undergraduate engineering students. This paper describes how to boost the student understanding regarding wind power generation by combining the use of advanced software tools normally used in the design of wind farms, such as System Advisor Model (National Renewable Energy Laboratory, NREL) and WindFarm (RESOFT) with lowpower wind turbines operating in self-consumption and gridconnected modes. Moreover, it is also described how wind turbines constitute an interesting option for distributed generation system in microgrids.
\end{abstract}

Key words. Wind power, wind turbine, wind farm, teaching, learning.

\section{Introduction}

Energy is a critical issue for the economic development of our society. In fact, energy demand is continuously increasing around the world, being necessary to guarantee a secure supply to residential or industry facilities. During many decades, fossil fuels have represented the main part of the sources of energy in all the countries, due to their advantages in terms of cost and performance. Nevertheless, the negative environmental impact of fossil fuels is moving to policy makers to increase the generation of electricity using renewable energy sources. In particular wind power and photovoltaic power plants [1] are gaining a lot of atraction. Recent studies have highlighted that the share of renewable sources in gross final energy consumption in the European Union has moved from less than $9 \%$ in 2004 to $20 \%$ in 2020 , while the EU targets is to raise this share up to $32 \%$ by 2030 [2].
The growing demand for qualified engineers with advanced knowledge and skills in renewable energies require not only these students to study theoretical concepts, but also to design experimental or laboratory practices in order to conduct experiments using real wind turbines and software for simulating wind farms. Hence, the design of new didactic proposals for the teaching of these subjects [3] is highly adviced. There is an extensive literature in the field of renewable energy research [4], although the number of works related to the teaching/learning process in this field is not so extensive. Wind power is one of the major renewable resources, alongside photovoltaic and hydropower. It is also the most promising one in many countries. Some studies have proposed the analysis of teaching activities related to wind-power generation. From the educational point of view, different didactic proposals have been put forward, most of them based on the use of simulation tools. This is the case of the paper presented in [5], where it was proposed an open-source solution for engineering students involved in the study of variable speed wind turbines. In [6] it is analyzed the Tucannon River Wind Farm project (267 MW installed capacity using 116 wind turbines) for an in-class seminar session focused to the students work on topics related to sustainability. Other authors have analysed the use of wind power systems for other applications, such as the design and installation of a wind-mill driven pump used for irrigation [7]. Finally, it is important to remark that other academics have proposed the use of web-based virtual laboratories for teaching renewable and sustainable energies, including wind power generation [8-10].

In this paper, it is described how lecturers involved in wind energy courses can improve their teaching processes by accurately combining laboratory simulation practices using free software tools with the management of low-power wind turbines (operating in selfconsumption or grid-connected modes). Finally, it is explained how to integrate wind turbines as a distributed generation system in a real microgrid case. 


\section{Proposal for teaching and learning wind energy systems}

The proposed model for teaching-learning wind energy systems consists of combining the theoretical concepts studied in face-to-face classes with practical activities that combine activities in physical laboratories with simulation activities using advanced software tools. Figure 1 shows the general scheme of the proposed framework. As it will be described below, this proposal aims to cover some important techno-economic issues in wind energy systems, such as the study of the main parts and control elements for wind turbines, the role of wind power in distributed generation systems and microgrids, the selection of wind turbines for a specific location or the calculation of the power generated by a wind farm.

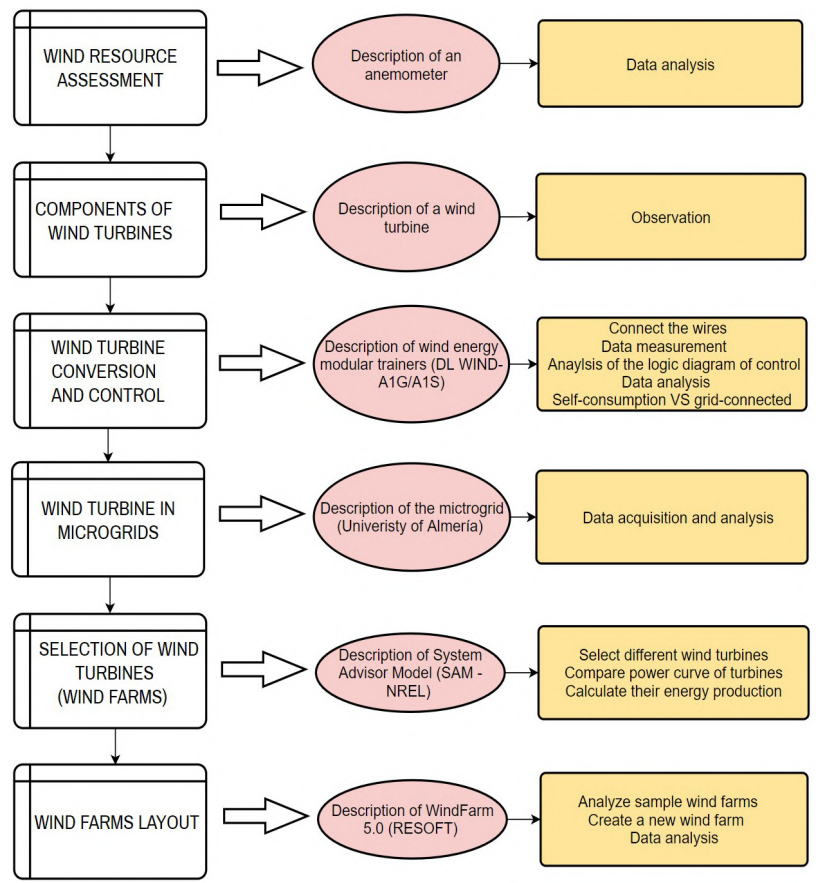

Fig. 1. Description of activities during the course (theory in capital letters, and practices in oval (lecturer actions) and rectangles (students' tasks).

\section{A. Wind resource assessment}

Wind resource assessment is the process of evaluating the future energy production of wind farms. Accurate wind energy resource assessment is critical to the successful development of wind farms. In this phase, the lecturer describes the main issues with respect to wind resource assessment, including an introduction to the nature of wind, short-term and long-term wind-speed variations, variation of wind speeds in the atmospheric boundary layer, and the importance of turbulences. Furthermore, they are described the instruments used for wind measurement, and wind-speed prediction and forecasting models, including the use of Weibull probability [11] and the Measure-Correlate-Predict (MCP) approach [12].

The lecturer can then propose an activity in which the students should analyse the data collected by an anemometer (see Figure 2).

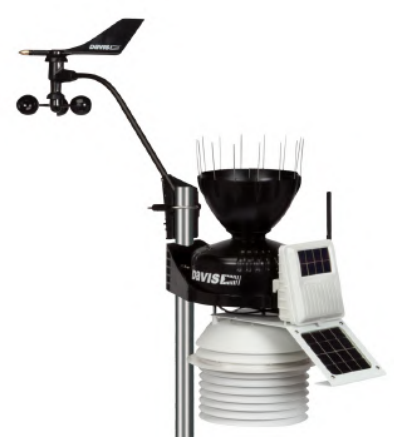

Fig. 2. Weather station with anemometer used in the laboratory.

\section{B. Components of wind turbines}

Another important milestone of the subject is to describe the physical characteristics of wind turbines. The lecturer should first describe the types of turbines, with special focus in establishing the advantages and disadvantages of horizontal-axis wind turbines (HAWT) with respect to vertical-axis wind turbines (VAWT). After that, the main elements of HAWT (blades, rotor hub, gearbox, generator, mechanical brake, nacelle, and tower) should be detailed. In this practice, the students should observe some interesting videos provided by the lecturer in order to explain the main characteristics of those elements.

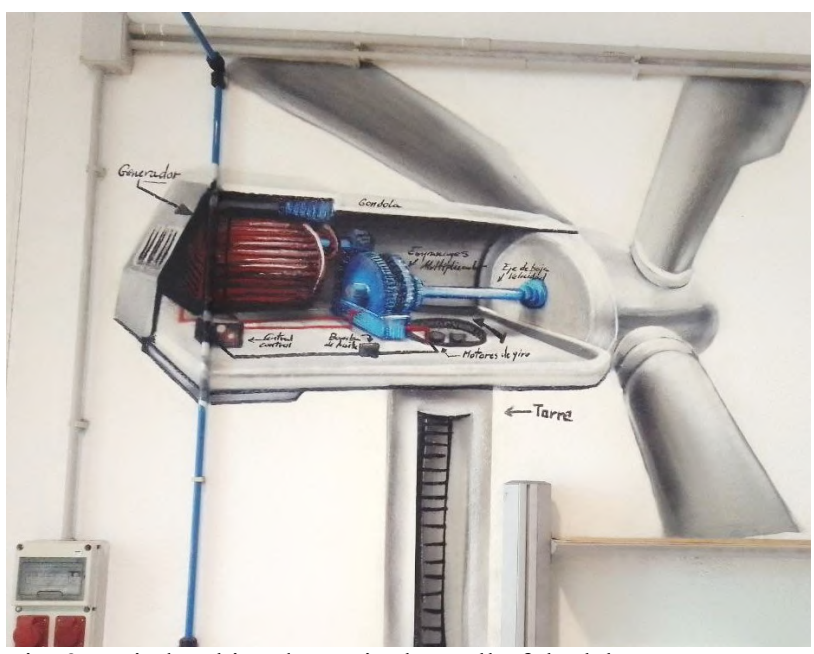

Fig. 3. Wind turbine drawn in the wall of the laboratory.

\section{Wind turbine energy conversion and control strategies}

Once the students are aware of the different types, characteristics and components of wind turbines, the next step should consist in explaining how wind energy is transformed in electrical energy. With this aim, the lecturer should introduce some basic concepts about wind turbine dynamics and aerodynamics, including parameters of airfoil wind turbine blades, low speed axis, gearbox, high speed axis and generator. It is particularly interesting to establish the differences between the rotors on grid-connected wind turbines that operate at constant speed (their rotational speed is nearly constant, determined by the electrical generator and the gearbox) and those operating at variable speed (which requires more complex and expensive power conversion 
equipment in the drive train and electrical components of the wind turbine) [13].

With that information, the lecturer should then introduce the equations governing the rotor power generation. With this aim, the lecturer should introduce the parameters that are involved in this calculation. More specifically, it should be indicated that the rotor power is as a function of the power coefficient $\left(C_{p}\right)$, the drive train efficiency $(\eta)$, the air density $(\rho)$, the rotor radius $(R)$, and the wind speed (U).

$$
P_{\text {rotor }}=C_{p} \eta \frac{1}{2} \rho \pi R^{2} U^{3}
$$

On the other hand, the students should acquire a basic knowledge about control strategies in HAWT. Wind turbine control system comprises of a number of sensors, actuators, and equipment and software which converts the input signals taken from the sensors and produces yield signals for the actuators. In particular, the lecturer should pay special attention to the description of the pitch control as the main strategy of controlling the aerodynamic power generated by the turbine rotor in contrast to (static) stall control.

With all the above information, the lecturer should design a practice using wind energy modular trainers. In this case, it is proposed the use of modular trainers WIND-A1G (grid-connected) and WIND-A1S (self-consumption) manufactured by De Lorenzo S.p.A. [14]:

- WIND-A1S: It is a didactic system for the study of the generation of electric energy from a wind turbine for self-consumption, that is, isolated from the grid. It includes a battery for regulating and charging $\mathrm{AC}$ and DC loads. Figure 3 shows the kit included in WINDA1S and Figure 4 presents the wire connection done by a group of students.

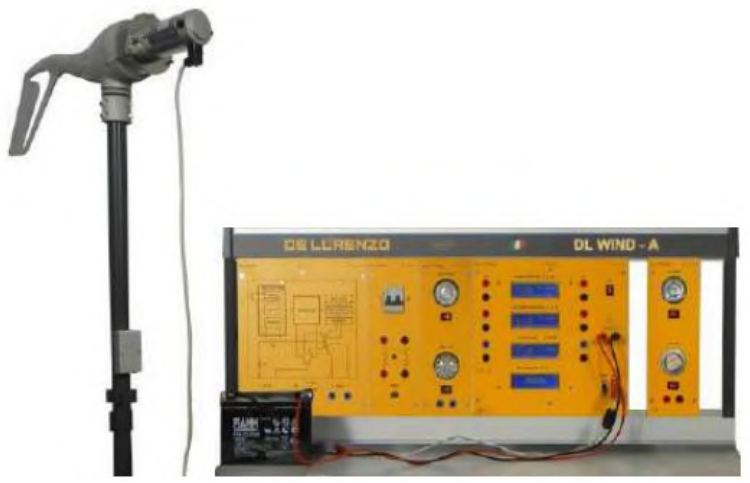

Fig. 3. Modular trainer DL WIND-A1S (De Lorenzo S.p.A.)

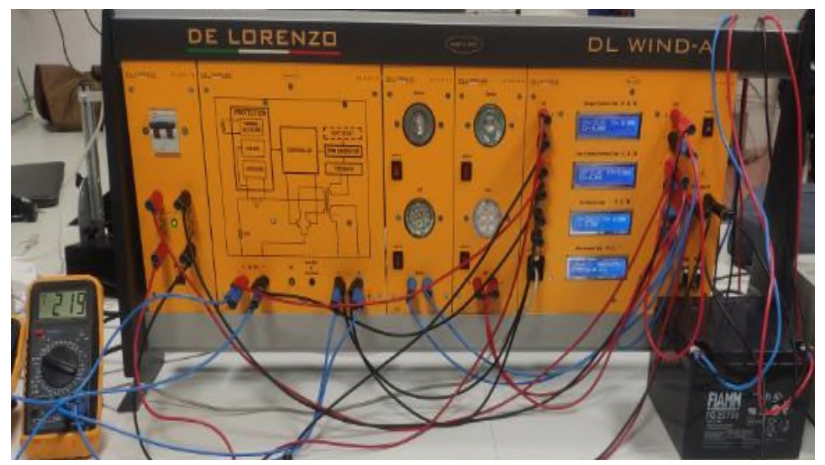

Fig. 4. Wires connected by students using DL WIND-A1S.
- WIND-A1G: It is a didactic system for the study of the generation of electric energy from a wind turbine and its connection to the grid. This trainer incorporates a $12 \mathrm{~V}$ generator, with three blades, although it also includes a stepper motor kit to drive the wind generator in absence of wind. This modular trainer allows to perform several exercises, including measuring the power generated, load and power balance, simulate island mode, and simulate grid faults. Figure 5 shows the kit included in WINDA1G and Figure 6 presents the wire connection done by a group of students for studying power balance in the system.
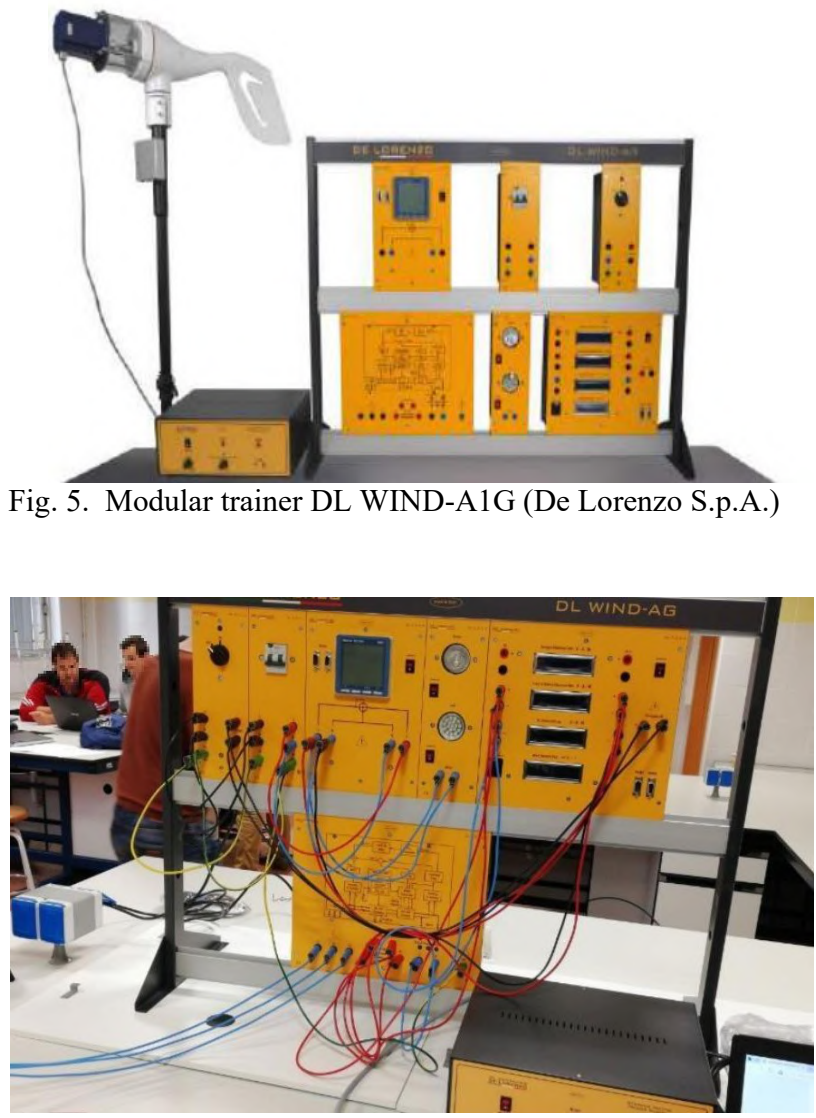

Fig. 6. Wires connected by students using DL WIND-A1G.

\section{Wind turbines in microgrids}

Microgrids are small-scale power systems that involve distributed energy resources, loads, and storage. Wind power is one of the main distributed energy resources considered in microgrids. Therefore, the next practical activity is related to the study of the integration of wind turbines in a real microgrid. With this purpose, the students should attend to a face-to-face session at the small-sacle microgrid that has been recently developed at the University of Almería (Spain). This microgrid includes generation from two photovoltaic solar trackers (12 photovoltaic panels each) and three wind turbines. These wind turbines correspond to the model "Wind $13+$ " manufactured by Bornay S.L., which features are summarized in Table I. 
Table I. - Main specifications of Wind 13+ turbine (Bornay)

\begin{tabular}{|l|c|}
\hline PARAMETER & VALUE \\
\hline Number of blades & 2 \\
\hline Diameter & $2.86 \mathrm{~m}$ \\
\hline Total weight & $63.8 \mathrm{~kg}$ \\
\hline Height of the rotor hub & Fiberglass $/$ Carbon fiber \\
\hline Material & Counterclockwise \\
\hline Direction of rotation & AC 3-phase permanent magnet \\
\hline Generator & $220 \mathrm{~V}, 600,1500 \mathrm{~W}$ \\
\hline $\begin{array}{l}\text { Nominal } \\
\text { voltage/rpm/power }\end{array}$ & $2-30 \mathrm{~m} / \mathrm{s}$ \\
\hline Operating range & $3 \mathrm{~m} / \mathrm{s}$ \\
\hline Turn on & $12 \mathrm{~m} / \mathrm{s}$ \\
\hline Nominal power & $14 \mathrm{~m} / \mathrm{s}$ \\
\hline Automatic brack system & $60 \mathrm{~m} / \mathrm{s}$ \\
\hline Maximum & \\
\hline
\end{tabular}

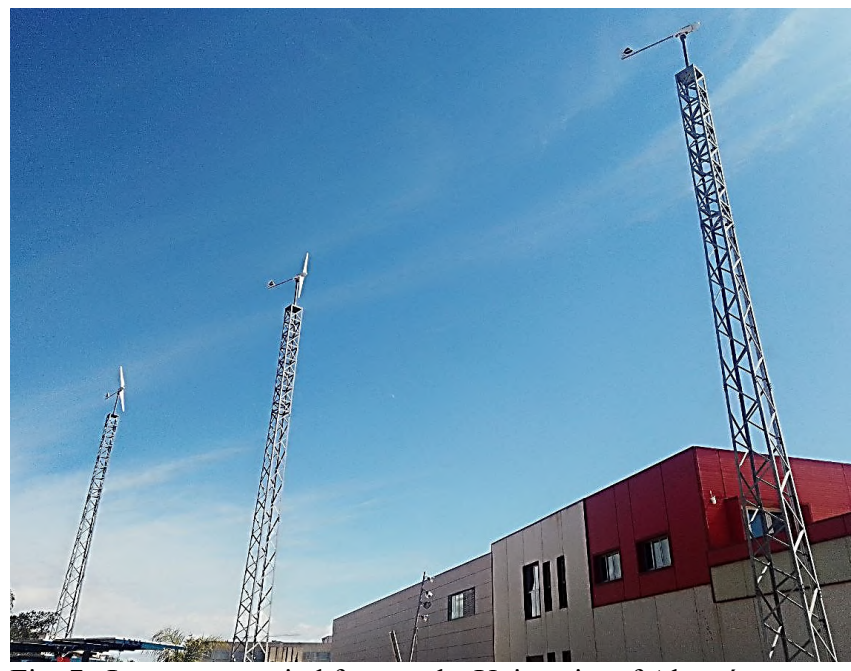

Fig. 7. Low-power wind farm at the University of Almería.

The layout of the low-power wind turbines is shown in Figure 7. The lecturer should explain that the location and disposal of wind turbines should be determined according to the wind speed and direction in order to increase the energy produced. Other aspects to consider are the environmental and visual impact of the wind turbines and the noise they generate.

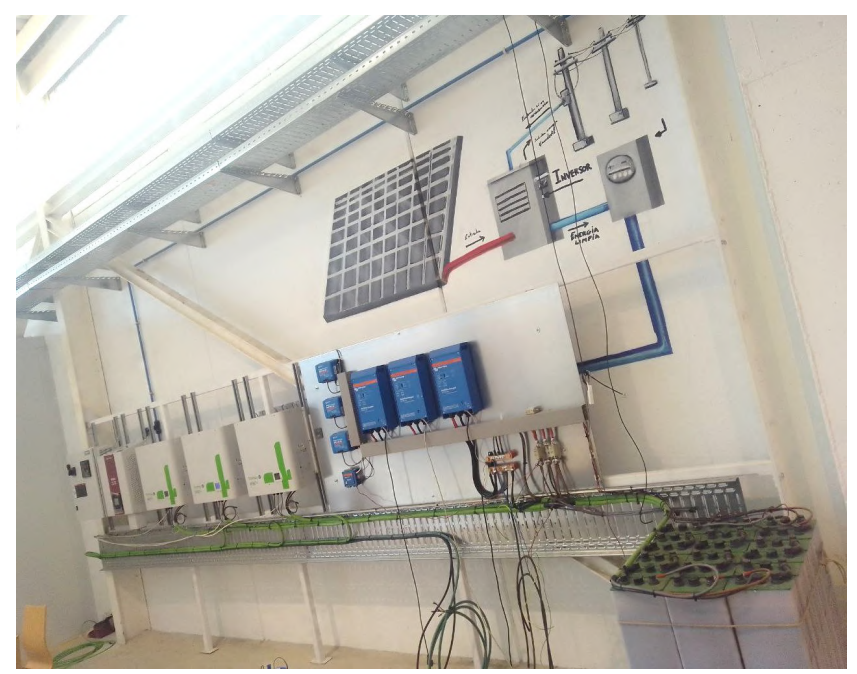

Fig. 8. Connection of the wind turbines to the battery bank.
As Figure 8 shows, the output of the wind turbines MPPT are connected using underground cables to the DC bus of the industrial warehouse using regulators, which control the wind turbines and the power it produces to charge the battery bank to which it is connected (the PV panels are connected to the DC bus using a solar charge that gathers energy from these solar panels and stores it in the batteries).

Figure 9 shows the structure of the microgrid located at the University of Almería. Therefore, in this activity, the lecturer should explain the structure of the microgrid and the students analyze the data displayed in the touch screen of the regulators (wind speed, rotor angular speed, internal temperature and battery power).

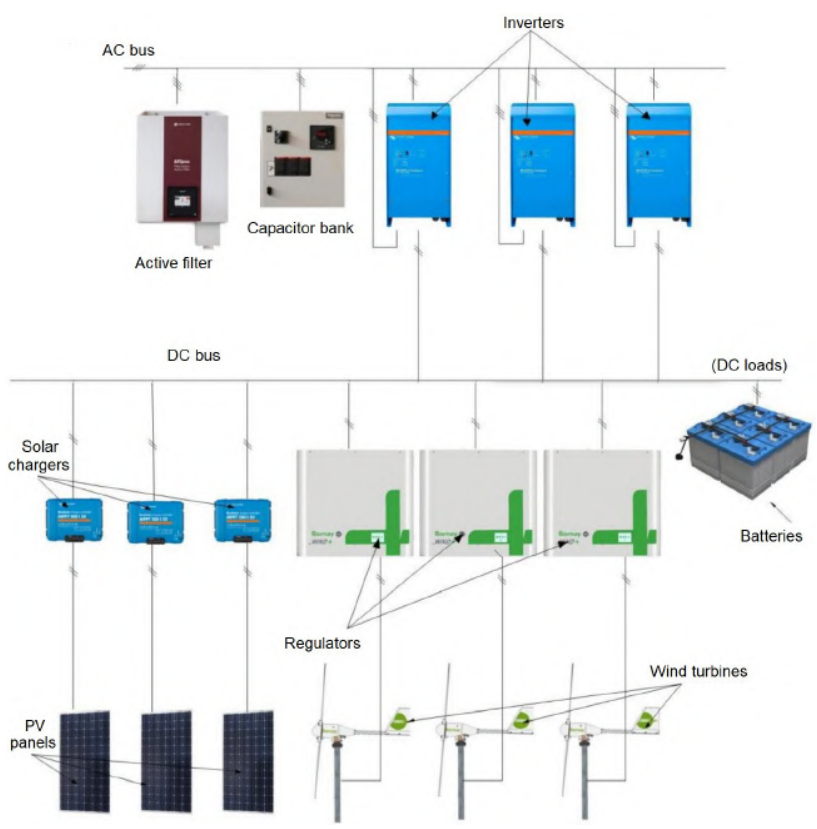

Fig. 9. Structure of the microgrid at the University of Almería.

\section{E. Siting selection and wind turbine selection}

At this point, the students should be ready to extend their knowledge to wind farms. The study of wind farms involves the consideration of several variables, including the location of the wind farm (wind farm siting) and the turbines to be installed in the wind farm with the main goal of maximizing the energy produced (revenue).

A given location is often evaluated depending on the mean power production for a wind turbine according to the power curve that is provided by manufacturers. Let us suppose there is available a series of $\mathrm{N}$ wind speed observations, Ui, each averaged over the time interval $\Delta \mathrm{t}$. Then it is possible to calculate the long-term average wind speed, $\bar{U}$, over the total period of data collection, as Equation (1) indicates:

$$
\bar{U}=\frac{1}{N} \sum_{i=1}^{N} U_{i}
$$

Furthermore, if $P_{w}\left(U_{i}\right)$ represents the power output defined by a wind machine power curve, then the average wind machine power, $\overline{P_{w}}$, is represented as:

$$
\bar{P}_{w}=\frac{1}{N} \sum_{i=1}^{N} P_{w}\left(U_{i}\right)
$$


Then, the energy yield of a wind turbine can be estimated (supposing 100\% availability) as Equation 3 shows:

$$
E_{w}=\sum_{i=1}^{N} P_{w}\left(U_{i}\right)(\Delta t)
$$

However, if precise wind speed data is not available for the location and height, but if projection of measured data from one location to another is required, or when only summary data are available, it is suitable to use analytical representations for the probability distribution of wind speed, as for example the Weibull distribution [11]. Furthermore, it is also suitable to consider supplementary data taken from wind atlas.

The initial site selection should be confirmed using a prediction of the long-term wind speed, for example using the measure-correlate-predict (MCP) method [12].

Additionally, other important decision here is to determine which turbine should be selected among the large number of models produced by the large list of manufacturers.

The practical activity designed for the lecturer consists of the students should use System Advisor Model (SAM), developed by the National Renewable Energy Laboratory (NREL) [15], to evaluate how the yearly generated energy can vary not only according to the site location but also depending of the selected turbine. Figure 10 shows a comparison performed by the students between two different turbines for the same location. Of course, it is also appropriate to establish a comparison of turbines in different locations.
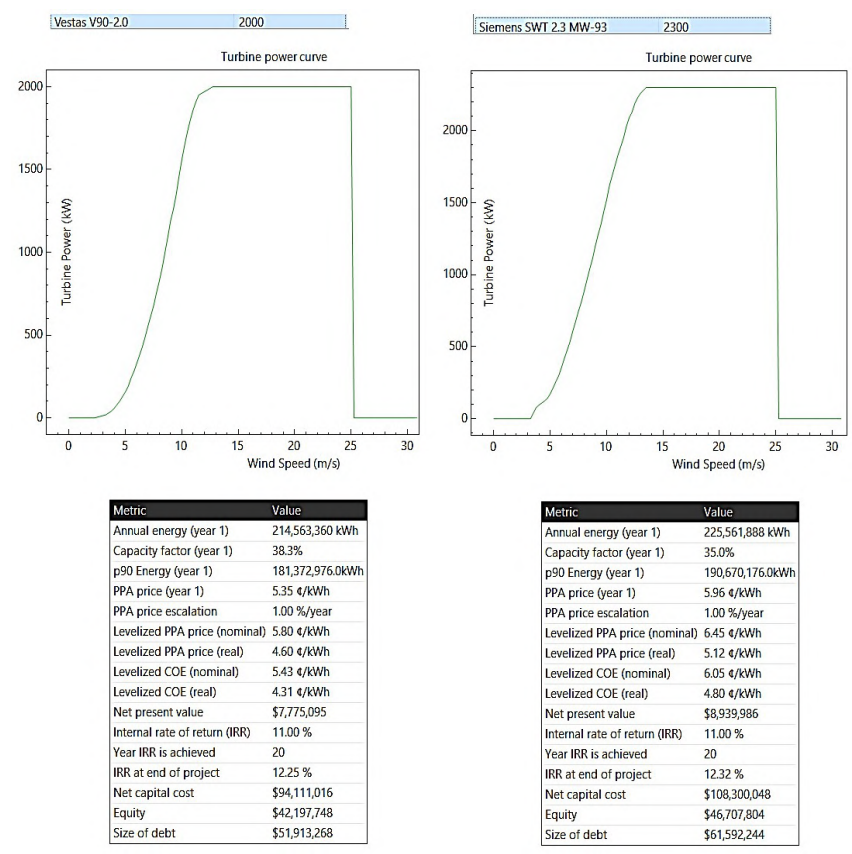

Fig. 10. Comparison of annual generated energy (kWh) by two different turbines (Vestas V90-2.0 and Siemens 2.3 MW-93 E66 20.7) in a flat location in Texas (U.S.) included in SAM database.

\section{F. Wind farms layout}

Finally, another important aspect the students should understand is the effect of wind farm layout in the maximization of the total yearly generated energy. This study often requires the use of advanced software tools [16] for the analysis of the topographic wind-speed variation and the wake losses (the reduction of wind speeds at downwind turbines due to wakes caused by upwind turbines).

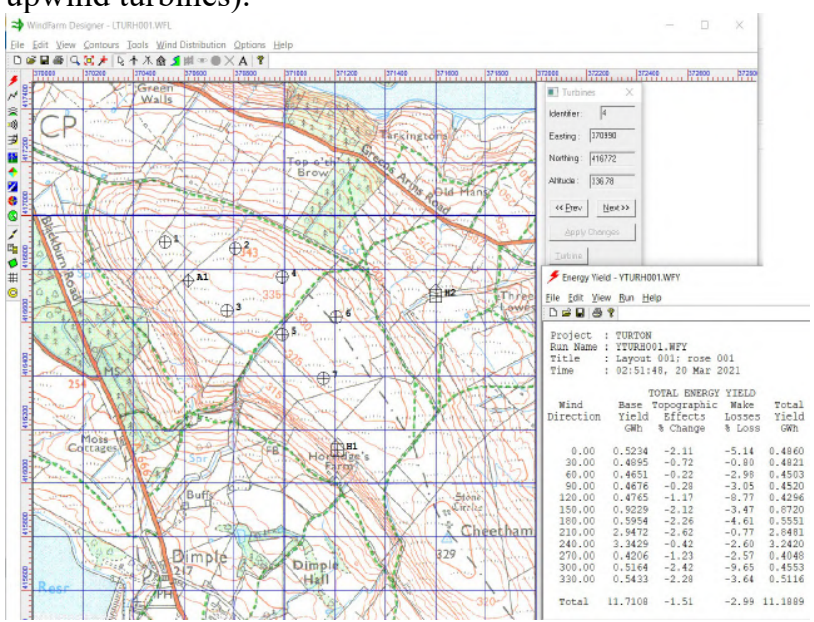

Fig. 11. Sample project "TURH" included in WindFarm DEMO version (see [17]).

With this aim, in this activity the lecturer should explain to the students the install process and use of WindFarm (RESOFT), a powerful system for wind farm development. The students should then analyze some sample case studies included in the free DEMO version of WindFarm to understand the effects of changing the layout of a wind farm considering the topography of the study area. In particular, the lecturer should propose the analysis of the sample project "TURH" included in WindFarm software. The students should modify the position of different wind turbines and analyze the energy yield of different configurations, in addition to existing studies already included in the software, such as the noise or the visual influence zone.

\section{Conclusion}

This paper presents a framework for improving the teaching-learning process in an undergraduate wind power systems course. This proposal has been carefully designed to facilitate the student understanding of wind energy systems, including the assessment of the wind resource, the study of the components of wind turbines, how wind is converted into energy using accurate control methods, the integration of wind turbines in microgrids, the selection of wind turbines and the optimization of the wind farm layout. To reach these objectives, a group of practical activities in laboratories and in a real microgrid have been performed in combination with the use of advanced wind energy software tools (SAM and WindFarm). The main advantage of this approach with respect to other alternatives is that the proposed method allows the students to validate the theoretical contents by means of practical activities in laboratories with autonomous computer-supported activities supporting these concepts that cannot be accurately addressed in face-to-face sessions at the university. Furthermore, this proposal can be used not only as teaching strategy for undergraduate electrical engineering students, but also for those graduated students of different disciplines interested in further study of wind energy systems and microgrids. This methodology can be also applied for those lecturers that teach other renewable energy matters 
such as solar photovoltaic systems. The main limitation of this methodology comes from the fact that some activities cannot be implemented for safety reasons, being then limited to the study of theoretical contents.

\section{Acknowledgement}

This study was partially supported by the Spanish Ministry of Science, Innovation and Universities (project PGC2018098813-B-C33). The authors also thank the University of Almería for their support to acquire and install the wind turbines used in the microgrid described in the paper.

\section{References}

[1] Özçiçek, Ö., Ağpak, F. "The role of education on renewable energy use: evidence from Poisson pseudo maximum likelihood estimations". Journal of Business \& Economic Policy (2017), Vol. 4, No. 4, pp. 49-61.

[2] Şahin, U. "Future of renewable energy consumption in France, Germany, Italy, Spain, Turkey and UK by 2030 using optimized fractional nonlinear grey Bernoulli model". Sustainable Production and Consumption (2021), Vol. 25, pp. 114.

[3] Kandpal, T.C., Broman, L. "Renewable energy education: A global status review", Renewable and Sustainable Energy Reviews (2014), Vol. 34, pp. 300-324.

[4] Vakulchuk, R., Overland, I., Scholten, D. "Renewable energy and geopolitics: A review". Renewable and Sustainable Energy Reviews (2020), Vol. 122, p. 109547.

[5] Fernández-Guillamón, A., Molina-García, Á. "Simulation of variable speed wind turbines based on open-source solutions: Application to bachelor and master degrees". The International Journal of Electrical Engineering \& Education (2021), 0020720920980974.

[6] McWhirter, N.D., Shealy, T. "Teaching decision-making for sustainable infrastructure: a wind energy case study module". International Journal of Sustainability in Higher Education (2018), Vol. 19, No. 5, pp. 893-911.

[7] El-Gabry, L., Jaskolski, M. "Offering engineering students global prospective through experiential learning project in wind energy and sustainability". Journal of Engineering for Gas Turbines and Power (2019), 141(10), pp. 101008.

[8] Deese, A. S. Development of smart electric power system (SEPS) laboratory for advanced research and undergraduate education. IEEE Transactions on Power Systems (2014), Vol. 30, No. 3, pp. 1279-1287.

[9] Ververidis, D., Chantas, G., Migkotzidis, P., Anastasovitis, E., Papazoglou-Chalikias, A., Nikolaidis, E., Nikolopoulos, S, Kompatsiaris, I, Mavromanolakis, G., Thomsen, L-E., Liapis, A., Yannakakis, G., Müller, M., Hadiji, F. An authoring tool for educators to make virtual labs. In International Conference on Interactive Collaborative Learning (pp. 653-666). Springer, Cham, 2018.

[10] Tourou, P., Einwächter, F., Sourkounis, C. Web-based interactive animated virtual experiments for teaching wind energy utilization. In 2013 15th European Conference on Power Electronics and Applications, (pp. 1-10). IEEE, 2013.

[11] Wais, P. "A review of Weibull functions in wind sector". Renewable and Sustainable Energy Reviews (2017), Vol. 70, pp. 1099-1107.

[12] Carta, J.A., Velázquez, S., Cabrera, P. "A review of measure-correlate-predict (MCP) methods used to estimate longterm wind characteristics at a target site". Renewable and Sustainable Energy Reviews (2013), Vol. 27, pp. 362-400.

[13] Manwell, J.F., McGowan, J.G., Rogers, A.L. Wind energy explained: theory, design and application (2010). John Wiley \& Sons.
[14] De Lorenzo. "Renewable Energies and Smart Grid - Wind" [Online]. Available: https://www.delorenzoglobal.com/renewable-energies/wind/ [Accessed: March, 19th, 2021]

[15] National Renewable Energy Laboratory. "System Advisor Model" [Online]. Available: https://sam.nrel.gov/ [Accessed: March, 19th, 2021]

[16] Burton, T., Sharpe, D., Jenkins, N., Bossanyi, E. Wind energy handbook Vol. 2 (2001). New York: Wiley.

[17] WindFarm DEMO version 5; ReSoft Ltd., London, UK Available: https://www.resoft.co.uk/Download// [Accessed: March, 19th, 2021]. 